\title{
Preface to the Special Topic on AdMet 2015
}

\author{
Volodymyr Shatokha $^{1} \cdot$ Shin-ya Kitamura ${ }^{2}$
}

Published online: 24 December 2015

(C) The Minerals, Metals \& Materials Society (TMS) 2015

The International Conference on Advances in Metallurgical Processes and Materials (AdMet 2015) was held in Kyiv, Ukraine, on June 3-5, 2015, and researchers and engineers from 12 countries attended the event. The first AdMet conference was held on 2007 in Dnipropetrovsk, Ukraine, and the second conference was initially planned for 2014. However, because of the political situation in Ukraine, it was rescheduled for 2015. Despite the intentions expressed by the organizers to relocate the conference to another country, they decided to keep it in Ukraine to reflect the substantial contributions made by Ukraine to the theory and practice of metallurgy. The local organization of AdMet 2015 was supported by the Paton Electric Welding Institute, National Metallurgical Academy of Ukraine, and Elmet-Roll Company.

Multidisciplinary cross-country collaboration is becoming increasingly important with respect to sustainable development targets. Therefore, the purpose of AdMet 2015 was to bring together researchers from the domains of process metallurgy and materials science in order to share the latest advances in research and development, assist international collaborations for solving current and future societal and technological challenges, and promote the transfer of innovative technologies and materials. The conference topics covered thermodynamics, innovative metallurgical processes, advances in iron- and steel-making technologies, process control, automation, online analysis, the design and properties of materials, modeling and simulation processes and materials, special melting, and environmental issues in metallurgy.

From the proceedings of AdMet 2015, we have chosen several articles that discuss the environmental issues in metallurgy, especially the recycling, recovery, and reuse of by-products and waste, to meet the scope of the Journal of Sustainable Metallurgy. In addition, one review paper discussing the present situation of the steel industry in Ukraine is included. We hope this special topic is useful to many researchers by providing updates on the recent advances in this field.

The third AdMet will be held in Lviv, Ukraine, in 2018, and it is our pleasure to invite the readers of the Journal of Sustainable Metallurgy to this conference.

The contributing editor for this article was Yiannis Pontikes.

\footnotetext{
Shin-ya Kitamura

kitamura@tagen.tohoku.ac.jp

1 National Metallurgical Academy of Ukraine, Dnipropetrovsk, Ukraine

2 Institute of Multidisciplinary Research for Advanced Materials, Tohoku University, Sendai, Japan
} 